\title{
Philosophische Anthropologie
}

Menschliche Selbstdeutung in Geschichte und Gegenwart

ron

\section{Dr. Michael Landmann}

o. Prof. für Philosophie an der Freien Univeraitut Berlin

3., tiberarbeitete und erwoiterte Anflage

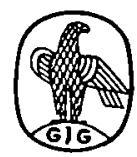

Sammlung Göschen Band 156 /156a

Walter de Gruyter \& Co - Berlin 1969

vormals G.J. Goschen'sche Verlagehandlung • J. Guttentag, Verlagobuchhandlung - Georg Reimer · Karl J. Trübner • Veit \& Comp. 
(C)

Copyright 1969 by Walter de Gruyter \& Co., vormals G. J. Göschen'sche Verlagshandlung - J. Guttentag, Verlagsbuchhandlung Georg Reimer - Karl J. Trübner - Veit \& Comp., Berlin 30. - Alle Rechte, einschl. der Rechte der Herstellung von Photokopien und Mikrofilmen, vom Verlag vorbehalten. Archiv-Nr. 7110698 - Satz: IBM-Composer, Walter de Gruyter \& Co. - Druck: E. Rieder, Schrobenhausen - Printed in Germany 